\title{
Universiteit
}

Leiden

The Netherlands

\section{Perceived uncertainties of characterization in LCA: a survey} Qin, Y.; Cucurachi, S.; Suh, S.

\section{Citation}

Qin, Y., Cucurachi, S., \& Suh, S. (2020). Perceived uncertainties of characterization in LCA: a survey. International Journal Of Life Cycle Assessment, 25, 1846-1858.

doi:10.1007/s11367-020-01787-9

Version: $\quad$ Publisher's Version

License: $\quad$ Licensed under Article 25fa Copyright Act/Law (Amendment Taverne)

Downloaded from: https://hdl.handle.net/1887/3201462

Note: To cite this publication please use the final published version (if applicable). 


\title{
Perceived uncertainties of characterization in LCA: a survey
}

\author{
Yuwei Qin ${ }^{1} \cdot$ Stefano Cucurachi ${ }^{2} \cdot{\text { Sangwon } \text { Suh }^{3}}^{3}$
}

Received: 11 April 2019 / Accepted: 23 June 2020 / Published online: 3 August 2020

(C) Springer-Verlag GmbH Germany, part of Springer Nature 2020

\begin{abstract}
Purpose Uncertainty analyses in life cycle assessment (LCA) literature have focused primarily on the life cycle inventory (LCI) phase, but LCA experts generally agree that the life cycle impact assessment (LCIA) phase is likely to contribute even more to the overall uncertainty of an LCA result. The magnitude of perceived uncertainties in characterization relative to that in LCI, however, has not been examined in the literature. Here, we use the pedigree approach to gauge the perceived uncertainty in the characterization phase relative to the LCI phase. In addition, we evaluate the level of approval on the pedigree approach as a means to characterize uncertainty in LCA.

Methods Applying the Numeral Unit Spread Assessment Pedigree (NUSAP) approach to environmental risk assessment literature, we extracted the criteria for evaluating the uncertainty in the characterization phase. We used expert elicitation to identify a pool of experts and conducted a survey, to which 47 LCA practitioners from 12 countries responded. In order to reduce personal biases in perceived geometric standard deviation (GSD) values, we used two reference questions on weight and life expectancy at birth for calibration.

Results Nearly half (49\%) of respondents expressed their approval to the pedigree matrix approach as a means of characterizing uncertainties in LCA, and responses were highly sensitive to the respondent's familiarity with the pedigree matrix. For instance, respondents who are highly familiar with the pedigree matrix were more polarized, with $15 \%$ and $19 \%$ of them expressing either strong approval or strong disapproval, respectively. Respondents less familiar with the pedigree approach were generally more favorable to its use. Compared with LCI, variability in characterization factors was influenced more strongly by geographical correlation and reliability of the underlying model, which showed 11 to $16 \%$ larger average GSDs when compared with the comparable criteria for LCI. Conversely, temporal correlation criterion was a less significant factor in characterization than in LCI.

Conclusions and discussion Overall, survey respondents viewed LCIA characterization as only marginally more uncertain than LCI, but with a wider variability in responses on characterization than LCI. This finding indicates the need for additional research to develop more thorough methods for characterizing uncertainties in life cycle impact assessment that are compatible with the uncertainty measures in LCI.
\end{abstract}

Keywords Uncertainty analysis · Impact assessment $\cdot$ Characterization factor $\cdot$ Life cycle assessment $\cdot$ Pedigree approach

Communicated By Ralph K. Rosenbaum

Electronic supplementary material The online version of this article (https://doi.org/10.1007/s11367-020-01787-9) contains supplementary material, which is available to authorized users.

Sangwon Suh

suh@bren.ucsb.edu

1 Department of Civil and Environmental Engineering, University of California, Berkeley, CA 94720, USA

2 Institute of Environmental Sciences (CML), Leiden University, 2333 CC Leiden, The Netherlands

3 Bren School of Environmental Science and Management, University of California, Santa Barbara, CA 93106, USA

\section{Introduction}

Life cycle assessment (LCA) is a decision-support tool that quantifies the environmental impacts of products throughout their life cycles (International Standard Organization 1997). Life cycle assessment often involves the use of uncertain data and models, measurement errors in input data, unrepresentative data, choices of system boundaries, underlying assumptions, and model incompleteness all of which contribute to uncertainty in the result (Lloyd and Ries 2007; Clavreul et al. 2012, 2013). Understanding the magnitude of uncertainty is essential in using LCA results for decision-making (Geisler et al. 2005; Sugiyama et al. 2005; Finnveden et al. 2009). 
A growing number of LCA studies address uncertainty issues (Cooper et al. 2012; Sills et al. 2012; Groen et al. 2014). But the majority of the uncertainty analyses in LCA focus on life cycle inventory (LCI) (Heijungs 1996; Maurice et al. 2000; Björklund 2002; Sonnemann et al. 2003; Gavankar et al. 2015; Scherer and Pfister 2016; von Pfingsten et al. 2017). One of the most widely used LCI database, ecoinvent, includes uncertainty values, e.g., the geometric standard deviation for a lognormal distribution, for $62.7 \%$ of its unit process data in ver. 3.4. (Wernet et al. 2016; Qin and Suh 2017). The professional LCA software tools including SimaPro and OpenLCA also provide uncertainty analysis functionality using Monte Carlo simulations, again mostly focusing on LCI (SimaPro 2016; OpenLCA 2018).

Both the LCI and life cycle impact assessment (LCIA) phases of LCA are data- and calculation-intensive, involving many model and data assumptions that can introduce errors (Huijbregts 1998a; Heijungs and Huijbregts 2004; Lloyd and Ries 2007; Reap et al. 2008; Gavankar et al. 2015). Few studies consider uncertainty from the characterization phase, and quantitative uncertainty assessments on characterization mostly focus on climate change impact category (Cellura et al. 2011; Hauschild et al. 2013). For example, Huijbregts (1998b) addressed the contribution of characterization factors to uncertainties in the global warming and acidification results of roof gutters. Huijbregts et al. (2003) further extended uncertainty analysis to parameter, scenario, and model uncertainties in a case study of two insulation models. Roy et al. evaluated parameter uncertainties in the characterization factor for terrestrial acidification (Roy et al. 2014). Later, a full uncertainty assessment of biofuels confirmed that both characterization factors and inventory uncertainties are essential incarbon and water scarcity footprints (Pfister and Scherer 2015). A study on characterization factors for ecotoxicity concluded that both parameter uncertainty and spatial variation should be accounted for in fate and exposure factors (Nijhof et al. 2016).

One major challenge is that characterization models do not typically provide uncertainty information for input parameters (Hung and Ma 2009; Noshadravan et al. 2013; Henriksson et al. 2015; Gregory et al. 2016). As a result, the influence of uncertainty in characterization models on the overall uncertainty of an LCA result is largely unknown (Hung and Ma 2009). But it is possible for characterization uncertainty to dominate the overall uncertainty of an LCA study. Characterization factors are calculated from simplified models of complex interacting physical and chemical systems that often require the linearization of non-linear relationships (Cucurachi et al. 2017). As a result, characterization models may carry larger uncertainties than LCI (Lloyd and Ries 2007).
Literature suggests that LCA practitioners tend to perceive larger uncertainty with the LCIA phase than the LCI phase (Owens 1997; Huijbregts 1998b; Clavreul et al. 2012). But to date, no study has attempted to quantify perceived uncertainties between LCI and characterization. Here, we use the expert elicitation procedure to gather perceptions about the uncertainty of LCI and characterization. We also created a pedigree matrix, which has been used for LCI data quality evaluation, for the characterization phase of LCIA. Next, we present the survey design and respondent demographics in the "Methods" section, results and pedigree matrix in the "Results" section, and discussion and conclusions in the "Discussion and conclusions" section.

\section{Methods}

This study combines the pedigree approach and expert elicitation approach using a survey.

\subsection{Pedigree matrix}

Uncertainty characterization in LCA using Monte Carlo simulations or global sensitivity analysis requires information about ranges or distributions of the underlying parameters. Experimental (empirical) measurements offer the best source for such ranges and distributions, but are unfortunately often unavailable. Absent such data, the pedigree method has often been used in LCA to translate qualitative characteristics of underlying parameters into quantitative variability metrics (Frischknecht and Rebitzer 2005).

The pedigree approach-originally inspired by the Numeral Unit Spread Assessment Pedigree (NUSAP) system - was proposed by Funtowicz and Ravetz (1990). The pedigree approach is essentially a method to estimate the quantitative uncertainties based on qualitative characteristics of a data set (Weidema and Wesnaes 1996; Weidema 1998). The study by Van den Berg et al. (1999) is an early example of a pedigree matrix which uses 15 criteria for characterizing uncertainty. The pedigree method has since come into widespread use. In the USA, the Environmental Protection Agency offers a guide on the development, management, and use of data quality information in LCA using a pedigree matrix (Edelen and Ingwersen 2018). The ecoinvent database has adopted the pedigree method since its version 2.0 (Althaus et al. 2007; Weidema et al. 2013). The ecoinvent database uses the this method to adjust default uncertainty values, which are either measured or estimated based on five qualitative uncertainty characteristics of the data: reliability, completeness, temporal correlation, geographical correlation, and technological correlation (Muller et al. 2014). The resulting uncertainty value is expressed as geometric standard deviation (GSD) of a lognormal distribution. GSD is a 
measure of the spread of lognormally distributed data points. For example, a GSD of 1.8 translates to one order of magnitude difference between the lower bound and the upper bound of a data set within the $95 \%$ confidence range.

The pedigree method enables quantitative uncertainty analysis absent measured variability information, and can be used to assess not only parameter uncertainties but also nonparametric uncertainties associated with the technical, methodological, and epistemic dimensions of a data set (Van Der Sluijs et al. 2005). Despite these strengths, at its core, the pedigree approach relies on the subjective judgments of experts, which raises questions about its usefulness and validity. Ciroth et al. (2013) compared empirical observations and the uncertainty characteristics derived using the pedigree approach of the ecoinvent database and found that it tended to underestimate underlying uncertainties (Ciroth et al. 2013). Yang et al. (2018) examined LCA results of major crops in the USA based on high-resolution spatial data and concluded that the uncertainty values of agricultural inputs based on the ecoinvent pedigree method lead to a large underestimation.

If nothing else, the pedigree method helps gauge perceived level of uncertainties in a data set when quantitative measurements are lacking. In this study, we employed the pedigree approach with various modifications to compare perceived uncertainties in characterization relative to those in LCI. We sent two sets of survey questions, one for characterization and another for LCA, to each expert. For LCI, we modified the pedigree matrix used in the ecoinvent database. For characterization, we created a new pedigree matrix based on NUSAP and environmental risk assessment literature (Funtowicz and Ravetz 1990; Jaworska and Bridges 2001; Van Der Sluijs et al. 2005; Ragas et al. 2009).

\subsection{Expert elicitation}

Expert elicitation is the use of expert judgment on a subject which has insufficient data because of physical constraints or a lack of knowledge (de Franca Doria et al. 2009; Knol et al. 2010; McBride and Burgman 2012; Morgan 2014). Expert elicitation has been used since the late 1960s, and was first used in the Delphi method to collect expert judgment on probability estimation (Brown et al. 1969; Amara and Lipinski 1971; Rowe and Wright 1999). The use of the knowledge and wisdom of experts can inform policies when scientific evidence is lacking and help address uncertainties when there is insufficient information. Elicitation of expert judgment also has been used in various science-policy contexts such as the Intergovernmental Panel for Climate Change (IPCC) (Rypdal and Winiwarter 2001), European Environmental Agency (Meozzi and Iannucci 2006), and the US Environmental Protection Agency (2005).

The key steps of conducting expert elicitation are summarized in Fig. 1 (Ayyub 2000; Knol et al. 2010). Under the

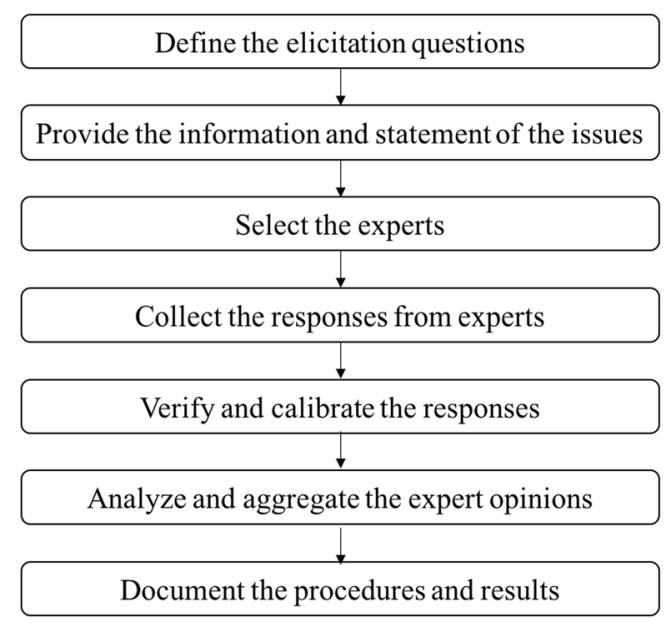

Fig. 1 Flow chart of expert elicitation procedures

expert elicitation process, experts receive a short description of the purpose of the expert elicitation and the conditions of their participation, as well as an explanation of the performance measures, uncertainties related to the studied problem, and key literature substantiating the problem (Cooke and Goossens 1990; Frey 1998). This information elicits the formation of responses to the questions. The purpose of the expert elicitation described here was to create a pedigree matrix for characterization factors. We provided background information of the pedigree matrix and graphic visualization of distributions with different GSDs so that the experts can better conceptualize the relationship between GSDs and corresponding shapes of the distribution.

The selection process involves identifying what expertise is relevant to the elicitation and selecting a sample of experts who can best satisfy the requirements of that expertise under time and resources constraints (Czembor and Vesk 2009; McBride and Burgman 2012). The quality of expert elicitation depends on the experts' knowledge, experience, and practice (Hickey and Davis 2003; Slottje et al. 2008; Martin et al. 2012). It is important to include a diverse range of experts because a large sample of experts can not only represent the whole community but also reduce the influence of individual mistakes and biases (Clemen and Winkler 1985; Armstrong 2008). We selected experts based on publication records from the Web of Science in the field of LCA and uncertainty analysis. We used the search keywords, "Life Cycle Assessment" and "uncertainty" (or "LCA" and "uncertainty") in the titles of peer-reviewed journal articles published over the last 20 years. We invited all the co-authors of the publications found using the search keywords to our survey.

After the collection of expert judgments, verification and calibration of the expert responses were performed. This step is essential in the analysis of the expert opinions because it can not only check for errors and consistencies in the responses but also compares the responses to other responses in the elicitation participation and other available information 
(Cooke 1991). The sources of bias and error include carelessness, misinterpretation, and overconfidence (Moore and Healy 2008). Calibration can be used to control overconfidence and inconsistency (Murphy and Daan 1984). Some methods involved in the calibration process are probability theory, aggregation method, and analysis of bias (Clemen and Winkler 1985). The purpose of the calibration is to "level the playing field", reducing the influence of bias and overconfidence and making the experts' responses consistent and close to expected true value (Winkler and Murphy 1968; Alpert and Raiffa 1982; Ferrell 1994). In our study, we used weight and life expectancy at birth to calibrate experts' ability to relate perceived distribution to a GSD value (see the "Calibration" section).

\subsection{Survey design and expert selection}

We sent the survey information to 197 potential respondents with varying experience levels in LCA. The survey invitation was personalized with recipient's name, and one reminder was sent 2 months after the first invitation. The web-based survey contained 12 questions and was coded in HTML format. The average completion time was about $16 \mathrm{~min}$. The full questionnaire and survey data can be found in the Supplementary information. Given the nature of the survey that involves human subjects, the survey was reviewed and approved by the Institutional Review Board at the University of California, Santa Barbara. The structure and the content of the survey are elaborated below.

\subsubsection{Background questions}

We asked the respondents about their affiliation types, the continents that they reside on, and their level of experience in LCA. Based on their responses, we assigned them into two groups as follows: group 1 (respondents with 6 or more years of experience in LCA and who are familiar with the pedigree approach), and group 2 (respondents with fewer than 6 years of experience or who are not familiar with the pedigree method (see Fig. S1 in SI)). We asked about their degree of approval regarding the use of the pedigree approach in estimating uncertainties.

\subsubsection{Pedigree matrix for $\mathrm{LCl}$}

In the survey, we asked experts to provide their opinions about the importance of each criterion to be included in the pedigree matrix for LCI (Table 1). For this pedigree matrix, we used the criteria that were provided in the previous versions of the pedigree matrix of data quality, including geographical correlation, temporal correlation, technological correlation, completeness, reliability, and sample size (Weidema 1998; Wernet et al. 2016). Because the current pedigree matrix that ecoinvent uses for data quality evaluation has five criteria, we used a Likert scale to allow respondents to indicate their perceived importance of including each criteria in the pedigree matrix, and then used the results to narrow criteria down to the top five. The Likert scale used the following five levels: strongly disagree, disagree, neutral, agree, and strongly agree.

We asked the respondents to provide their perceived GSDs for all six criteria in the pedigree matrix used for evaluating LCI data quality. We provided descriptions of criteria in the original pedigree matrix used for LCI data quality evaluation for each uncertainty level for each criterion, but did not show the actual GSDs (Weidema 1998; Wernet et al. 2016). Instead, respondents input their perceived GSD scores under each criteria description. To help respondents to better link GSDs with their conceptual thinking regarding uncertainty, we provided frequency density plots of lognormal distributions for different GSDs.

\subsubsection{Pedigree matrix for characterization factors}

We developed the pedigree matrix for characterization factors and let the respondents indicate the importance of each criterion to be included in the matrix. Similar to the pedigree questions for LCI, we used a Likert scale to gather their opinions on the importance of each criterion to be included in the pedigree matrix for characterization factors. The six proposed criteria were level of consensus, model completeness, temporal specification, geographical specification, reliability of underlying science, and input data characteristics. For consistency with the pedigree matrix used in LCI, we let respondents indicate the importance of each criterion and then selected the top five for inclusion in the final version of the pedigree matrix for characterization factors. We also asked experts their perceived GSDs for all criteria.

The criteria for the LCI and characterization models are reproduced in Table 1 along with descriptions.

At the end of the survey, we also collected suggestions and concerns regarding the use of the pedigree matrix in LCA uncertainty estimation. More than half (53\%) of the respondents submitted their suggestions as well as their concerns in the survey. The concerns and recommendations are summarized in the "Discussion and conclusions" section.

\subsection{Survey analysis}

A total of 47 experts from various countries and levels of experience responded to the survey. Among the 47 responses we received, 23 were in group 1 with at least 6 years of experience in LCA and familiarity with the pedigree approach. The remaining 24 respondents were assigned to group 2 . To find whether the pedigree scores were different between the two groups, we used non-paired $t$ test to determine the statistical 
Table 1 Pedigree matrix criteria for LCI and characterization factors

\begin{tabular}{|c|c|c|c|}
\hline Criteria for LCI & Purpose & $\begin{array}{l}\text { Criteria for characterization } \\
\text { factors }\end{array}$ & Purpose \\
\hline Completeness & $\begin{array}{l}\text { Measure of the representativeness of the } \\
\text { data based on statistics }\end{array}$ & Model completeness & $\begin{array}{l}\text { Measure of the coverage of the } \\
\text { characterization } \\
\text { factors for the elementary flows in life } \\
\text { cycle inventory }\end{array}$ \\
\hline Reliability & $\begin{array}{l}\text { Indicator of whether the data is based on } \\
\text { measurement or assumptions }\end{array}$ & $\begin{array}{l}\text { Reliability of underlying } \\
\text { science }\end{array}$ & $\begin{array}{l}\text { Indicator of the reliability of the underlying } \\
\text { science of the method }\end{array}$ \\
\hline Temporal correlation & $\begin{array}{l}\text { Addresses the temporal difference } \\
\text { between } \\
\text { the data and the process under study }\end{array}$ & Temporal specification & $\begin{array}{l}\text { Addresses the level of temporal dynamics } \\
\text { in characterization modeling }\end{array}$ \\
\hline Geographical correlation & $\begin{array}{l}\text { Measure of the difference in the } \\
\text { geographical dimension between the } \\
\text { data and the process under study }\end{array}$ & Geographical specification & $\begin{array}{l}\text { Measure of the regional resolution of } \\
\text { characterization models }\end{array}$ \\
\hline $\begin{array}{l}\text { Technological } \\
\text { correlation }\end{array}$ & $\begin{array}{l}\text { Measure of the technological difference } \\
\text { between the data and the process } \\
\text { under study }\end{array}$ & Level of consensus & $\begin{array}{l}\text { Indicator of the level of consensus in } \\
\text { characterization methods }\end{array}$ \\
\hline Sample size & Measure of the sample size of the data & Input data characteristics & $\begin{array}{l}\text { Indicator of the level of empirical support } \\
\text { to the parameters used in characterization } \\
\text { modeling }\end{array}$ \\
\hline
\end{tabular}

significance of the difference between the means of the two groups.

To evaluate the importance of the criterion to be included in the pedigree matrix, we calculated the average scores from the Likert scales for the criteria. We mapped the Likert scales to a linear range such that 1 meant strongly disagree and 5 meant strongly agree. In our version of the pedigree matrices, we only selected the top five criteria based on the respondents' selections and included the criteria and the GSDs for the selected criteria into the pedigree matrix for LCI and characterization factors.

\subsubsection{Calibration}

We also used calibrated responses in order to minimize personal biases in relating a perceived distribution to corresponding GSD value. First, we provided the GSD value of the height of American adult males, which was 1.04 (Fryar et al. 2012). We then let the respondents provide their "best estimate" of the distributions for (1) the weights of American adult males and (2) the life expectancies at birth of the global population, which were 1.07 and 1.1, respectively (Fryar et al. 2012; CIA 2018). We assumed a linear relationship between actual GSD and the GSD in the response as shown in Eq. 1:

$\widehat{\mathrm{GSD}}=a \times \mathrm{GSD}_{\text {survey }}+b$

where $a$ and $b$ are the slope and $y$-intercepts used to calibrate responses, and the GSD terms are described above. In addition, we explained - and assumed that the survey respondents understood - that GSD $=1$ when there is no uncertainty, which provides the second equation to derive both $a$ and $b$ as shown below. As an example of the calibration process, recall that the actual GSD for the distribution of the weights of American males is 1.07. If a respondent estimated it to be 1.1 , then we calibrated the respondent's GSD estimates by solving the following system of equations:

$\left\{\begin{array}{c}1=a \times 1+b \\ 1.07=a \times 1.1+b,\end{array}\right.$

which results in:

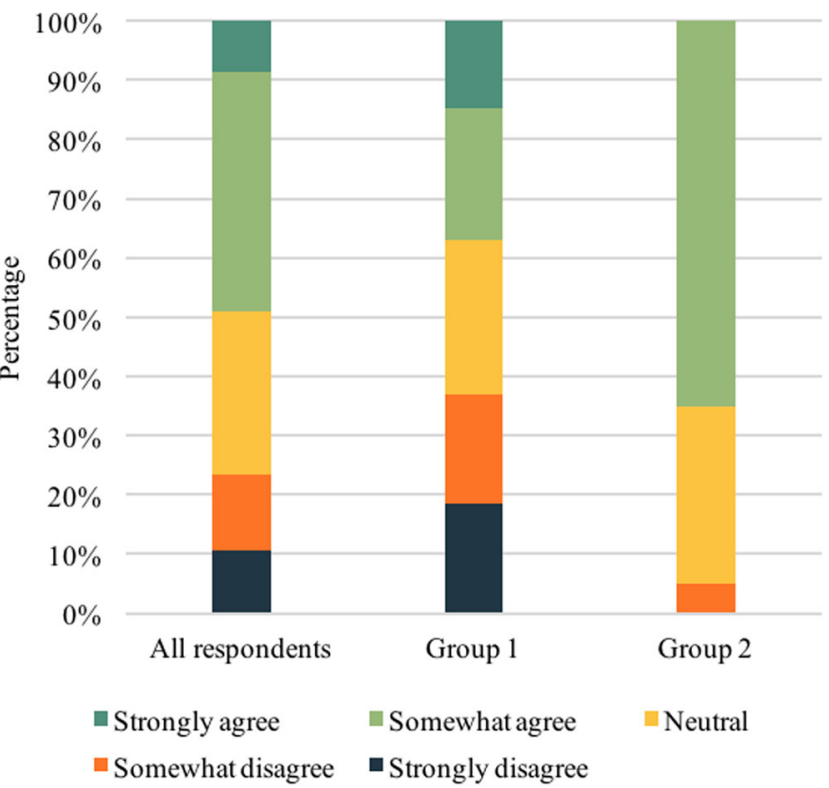

Fig. 2 Survey results for the question of the use of the pedigree approach for uncertainty quantification in LCA data 


$$
\widehat{\mathrm{GSD}}=0.7 \mathrm{GSD}_{\text {survey }}+0.3
$$

We calculated the expected GSD from both weight and life expectancy at birth for each respondent and used the average of $a$ and $b$ as the coefficients for the expected GSD equation to calibrate all GSDs.

\section{Results}

We analyzed the survey data and created the pedigree matrix based on the top five selected criteria in the matrix and GSDs for each uncertainty level for each criterion for both LCI and the characterization factors. The GSDs calibrated by weight and life expectancy at birth for the pedigree matrices of LCI and characterization factors are shown in Tables 3 and 4 . Uncalibrated GSDs are in Tables S1 and S2. For the sake of comparison, calibrated GSDs by the second version of ecoinvent pedigree scores which removes the indicator "sample size" for characterization factors also are given in Tables S1 and S2 in the Supplementary information.

\subsection{Survey demographics}

Most (72\%) respondents reported that they had been working in the LCA field for at least 6 years: $36 \%$ had worked more than 10 years and $26 \%$ had worked in the field for 1 to 6 years. The majority of the respondents worked in the academia (72\%). Of the remaining respondents, $13 \%$ worked in a corporation, $9 \%$ worked at consulting firms, and $6 \%$ worked at governmental organizations/research centers. Most respondents were in North America (49\%) and Europe (34\%), with $13 \%$ and $4 \%$ from Asia and South America, respectively. Additional details can be found in the Supplementary information (Figs. S2-S5).

\subsection{The degree of approval of the use of the pedigree approach for uncertainty quantification in LCA data}

Approximately half of respondents expressed their approval to the use of the pedigree matrix to estimate uncertainty in LCA data (Fig. 2). However, group 1 respondents with 6 or more years of experience were more likely to disagree with the use of the pedigree matrix for estimating uncertainty than group 2 respondents with fewer than 6 years of experience. As much as $38 \%$ of the respondents in group 1 disagreed or strongly disagreed with the use of the pedigree method for uncertainty estimation, while only $5 \%$ of the respondents in group 2 disagreed. No respondents from group 2 strongly disagree or strongly agree to the use of the pedigree approach in uncertainty quantification, reflecting a lack of polarization in this group.
We also received comments about the level of acceptance for the use of the pedigree matrix in characterizing uncertainties in LCA. Some respondents strongly disapproved of the use of the pedigree method, largely on the ground of the lack of empirical support to the approach, while others strongly supported the use of the pedigree method given the lack of information about quantitative uncertainty. One respondent commented that "LCA practitioners do not have an accurate intuitive sense of what is the GSD of the pedigree matrix." Some respondents found it difficult to provide uncertainties even when they had sufficient experience in this field, partly because the uncertainty characteristics would depend on the characterization models in question. For example, one respondent noted that "GWP and freshwater toxicity will express uncertainties at different orders of magnitude." Such responses are reasonable given that the characterization model for ecotoxicity is regionally sensitive, but that climate change is not. Thus, applying the same GSDs for multiple-impact categories is not appropriate. One respondent recommended using "the distribution coming from the characterization model directly" incorporating empirical data instead of using the pedigree approach.

However, some respondents commented that they support the use of the pedigree approach for the purpose of filling in the gaps in the uncertainty information in LCIA. One respondent commented that the method "would indeed be worthwhile to quantify the uncertainty of LCIA models". Another respondent noted that "the method could be useful in the absence of uncertainty data".

\subsection{Criteria to be included in the pedigree matrix}

We asked respondents to what extent they agreed or disagreed with including each of the six criteria in the pedigree matrices for LCI and characterization factors. As described in the "Survey analysis" section, we mapped the Likert scale to numerical values from 1 to 5 representing strongly disagree to strongly agree. Table 2 and Table 3 show the ranking and average scores of the six criteria used in our study.

\subsubsection{Criteria for $\mathrm{LCl}$}

Table 2 presents the rankings of pedigree matrix criteria of LCI. For LCI, both geographical correlation and temporal correlation were ranked as the top criteria to be included in the pedigree matrix. These criteria were followed by completeness, technological correlation, and reliability. Group 1 tended to rank technological correlation higher than completeness and reliability, whereas group 2 ranked reliability and sample size higher than technological correlation. Ultimately, we included temporal correlation, geographical correlation, completeness, 
Table 2 The pedigree matrix criteria selected for LCI and mean scores $(1=$ strongly disagree, $2=$ disagree, $3=$ neutral, $4=$ agree, and $5=$ strongly agree)

\begin{tabular}{lllllll}
\hline Rank & All respondents & Score & Group 1 & Score & Group 2 & Score \\
\hline 1 & Geographical correlation & 4.11 & Geographical correlation & 4.11 & Geographical correlation & 4.10 \\
2 & Temporal correlation & 4.11 & Temporal correlation & 4.11 & Temporal correlation \\
3 & Completeness & 3.91 & Technological correlation & 4.00 & Completeness & 4.10 \\
4 & Technological correlation & 3.89 & Completeness & 3.81 & Reliability & 3.05 \\
5 & Reliability & 3.83 & Reliability & 3.74 & Sample size & 3.95 \\
6 & Sample size & 3.32 & Sample size & 2.89 & Technological correlation & 3.75 \\
\hline
\end{tabular}

technological correlation, and reliability into the pedigree matrix for LCI (Table 4).

\subsubsection{Criteria for characterization factors}

For characterization factors, both group 1 and group 2 agreed upon with the same ranking. Temporal specification was the most important criterion to be included in the pedigree matrix for characterization factors, followed by geographical specification, model completeness, reliability of underlying science, input data characteristics, and level of consensus (Table 3). The average score of level of consensus responded by group 1 is below 3 (neutral). We included temporal specification, geographical specification, model completeness, reliability of underlying science, and input data characteristics into the pedigree matrix for characterization factors (Table 5).

\subsection{Pedigree matrix obtained from the survey}

The respondents were asked to provide their best estimates of GSDs for each level of uncertainty for each criterion for LCI and characterization factor, as well as the GSDs for weight and life expectancy at birth where the uncertainty is known. The purpose of the GSDs for weight and life expectancy at birth was to calibrate a broad range of expert opinions. Overall, respondents tended to overestimate the GSDs for the distribution of weight and life expectancy at birth. The average ratios of the surveyed GSD to the actual GSD for distributions of weight and life expectancy at birth were $111 \%$ and $118 \%$, respectively. The resulting average $a$ and $b$ of Eq. (1) were 0.60 and 0.40 , respectively.

\subsubsection{Pedigree matrix for $\mathrm{LCl}$}

Table 4 shows the pedigree matrix generated by averaging the responses after the calibration using the distributions of weight and life expectancy at birth. Both group 1 and group 2 gave similar GSD responses to LCI uncertainties. We performed a non-paired $t$ test for the two groups and found no significant difference between the average of the answers of the two groups to all of the cell entries, as the $p$ value was much larger than 0.05 , while group 1 tended to give slightly higher GSDs (3\%) than group 2.

We also compared the GSDs that respondents provided for the LCI pedigree matrix with GSDs that the pedigree matrix of ecoinvent uses (Fig. 3). We found that respondents generally estimated higher GSDs for LCI than those estimated by ecoinvent. The average ratios of non-calibrated GSDs and calibrated GSDs to ecoinvent-based GSDs were 1.19 and 1.06, respectively, which means that the GSDs after calibration were closer to the GSDs used by ecoinvent. When comparing respondents' GSDs to the GSDs in Ciroth et al. (2013), which is shown in Fig. 4, there was no clear trend. Respondents gave lower GSDs to reliability and further technology correlation criteria and higher GSDs for completeness, temporal correlation, and geographical correlation criteria.

Table 3 The pedigree matrix criteria for characterization factors and mean scores $(1=$ strongly disagree, $2=$ disagree, $3=$ neutral, $4=$ agree, and $5=$ strongly agree)

\begin{tabular}{lllllll}
\hline Rank & All respondents & Score & Group 1 & Score & Group 2 \\
\hline 1 & Temporal specification & 4.05 & Temporal specification & 3.96 & Temporal specification \\
2 & Geographical specification & 3.93 & Geographical specification & 3.81 & Geographical specification & 4.19 \\
3 & Model completeness & 3.70 & Model completeness & 3.56 & Model completeness & 3.11 \\
4 & Reliability of underlying science & 3.59 & Reliability of underlying science & 3.41 & Reliability of underlying science & 3.83 \\
5 & Input data characteristics & 3.42 & Input data characteristics & 3.19 & Input data characteristics & 3.76 \\
6 & Level of consensus & 3.09 & Level of consensus & 2.89 & Level of consensus \\
\hline
\end{tabular}


Table 4 The pedigree matrix for LCI from the survey results with GSDs calibrated using GSDs of distributions of weight and life expectancy at birth

\begin{tabular}{|c|c|c|c|c|c|c|}
\hline \multirow{2}{*}{\multicolumn{2}{|c|}{ Criteria }} & \multicolumn{5}{|l|}{ Score } \\
\hline & & 1 (Low uncertainty) & $\begin{array}{l}2 \text { (Moderately low } \\
\text { uncertainty) }\end{array}$ & $\begin{array}{l}3 \text { (Moderate } \\
\text { uncertainty) }\end{array}$ & 4 (Moderately high uncertainty) & 5 (High uncertainty) \\
\hline \multirow[t]{2}{*}{1} & \multirow[t]{2}{*}{ Reliability } & $\begin{array}{l}\text { Verified data based on } \\
\text { measurement }\end{array}$ & $\begin{array}{l}\text { Verified data partly } \\
\text { based on } \\
\text { assumptions or } \\
\text { non-verified data } \\
\text { based on mea- } \\
\text { surements }\end{array}$ & $\begin{array}{l}\text { Non-verified data } \\
\text { partly based on } \\
\text { assumptions }\end{array}$ & $\begin{array}{l}\text { Qualified estimate (e.g., by } \\
\text { industrial expert) }\end{array}$ & Non-qualified estimate \\
\hline & & 1.00 & 1.09 & 1.20 & 1.32 & 1.59 \\
\hline \multirow[t]{2}{*}{2} & \multirow[t]{2}{*}{ Completeness } & $\begin{array}{l}\text { Representative data from } \\
\text { a sufficient sample of } \\
\text { sites over an adequate } \\
\text { period to even out } \\
\text { normal fluctuations }\end{array}$ & $\begin{array}{l}\text { Representative data } \\
\text { from a smaller } \\
\text { number of sites } \\
\text { but for adequate } \\
\text { periods }\end{array}$ & $\begin{array}{l}\text { Representative } \\
\text { data from an } \\
\text { adequate } \\
\text { number of sites } \\
\text { but from shorter } \\
\text { periods }\end{array}$ & $\begin{array}{l}\text { Representative data but from a } \\
\text { smaller number of sites and } \\
\text { shorter periods or incomplete } \\
\text { data from an adequate number } \\
\text { of sites and periods }\end{array}$ & $\begin{array}{l}\text { Representativeness } \\
\text { unknown or } \\
\text { incomplete data from a } \\
\text { smaller number of } \\
\text { sites and/or from } \\
\text { shorter periods }\end{array}$ \\
\hline & & 1.00 & 1.09 & 1.18 & 1.29 & 1.55 \\
\hline \multirow[t]{2}{*}{3} & \multirow[t]{2}{*}{$\begin{array}{l}\text { Temporal } \\
\text { correlation }\end{array}$} & $\begin{array}{l}\text { Less than } 3 \text { years of } \\
\text { difference to year of } \\
\text { study }\end{array}$ & $\begin{array}{l}\text { Less than } 6 \text { years } \\
\text { difference }\end{array}$ & $\begin{array}{l}\text { Less than } 10 \text { years } \\
\text { difference }\end{array}$ & Less than 15 years difference & $\begin{array}{l}\text { Age of data unknown or } \\
\text { more than } 15 \text { years of } \\
\text { difference }\end{array}$ \\
\hline & & 1.00 & 1.09 & 1.18 & 1.29 & 1.51 \\
\hline \multirow[t]{2}{*}{4} & \multirow[t]{2}{*}{$\begin{array}{c}\text { Geographical } \\
\text { correlation }\end{array}$} & $\begin{array}{l}\text { Data from area under } \\
\text { study }\end{array}$ & $\begin{array}{l}\text { Average data from } \\
\text { larger area in } \\
\text { which the area } \\
\text { under study is } \\
\text { included }\end{array}$ & $\begin{array}{l}\text { Data from area } \\
\text { with similar } \\
\text { production } \\
\text { conditions }\end{array}$ & $\begin{array}{l}\text { Data from area with slightly } \\
\text { similar production conditions }\end{array}$ & $\begin{array}{l}\text { Data from unknown area } \\
\text { or area with very } \\
\text { different production } \\
\text { conditions }\end{array}$ \\
\hline & & 1.00 & 1.09 & 1.16 & 1.28 & 1.57 \\
\hline \multirow[t]{2}{*}{5} & \multirow[t]{2}{*}{$\begin{array}{l}\text { Technological } \\
\text { correlation }\end{array}$} & $\begin{array}{l}\text { Data from enterprises, } \\
\text { processes, and } \\
\text { materials under study }\end{array}$ & $\begin{array}{l}\text { Data from processes } \\
\text { and material } \\
\text { under study but } \\
\text { from different } \\
\text { enterprises }\end{array}$ & $\begin{array}{l}\text { Data from } \\
\text { processes and } \\
\text { materials under } \\
\text { study but from } \\
\text { different } \\
\text { technology }\end{array}$ & $\begin{array}{l}\text { Data on related processes or } \\
\text { materials but same technology }\end{array}$ & $\begin{array}{l}\text { Data on related processes } \\
\text { or materials but } \\
\text { different technology }\end{array}$ \\
\hline & & 1.00 & 1.08 & 1.22 & 1.33 & 1.63 \\
\hline
\end{tabular}

\subsubsection{Pedigree matrix for characterization factors}

Table 5 shows the pedigree matrix of the calibrated GSDs for characterization factors. Non-calibrated GSD results can be found in Supplementary Information (Table S2). Similar to the LCI results, group 1 gave higher GSDs than group 2 on average, and the average ratio of GSDs from group 1 to group 2 was 1.08 . We also performed statistical non-paired $t$ test between the average of the answers of the two groups to find whether the two groups provided significantly different GSDs, and found their responded GSDs were not significantly different.

\subsection{Comparison of GSDs for LCl and characterization factors}

We also compared GSDs for LCI and characterization factors provided by the respondents to find which LCA phase has higher perceived uncertainty (Fig. 5). In general, GSDs for characterization factors were statistically slightly larger (3\%) than those for LCIs. Respondents gave higher uncertainty scores for geographical correlation and reliability criteria. These differences were again statistically significant. Respondents also gave slightly higher uncertainty scores for the completeness criterion for characterization factors than those for LCI. For temporal correlation, respondents gave lower uncertainty scores for characterization factors than for LCI. The criterion for LCI, technological correlation, and the criterion for characterization factors, input data characteristics, are not comparable, but the respondents provided similar GSDs for them.

\section{Discussion and conclusions}

In this study, we surveyed and analyzed the perceived uncertainties in characterization factors relative to those in LCI using an expert elicitation approach. Perceived uncertainties 


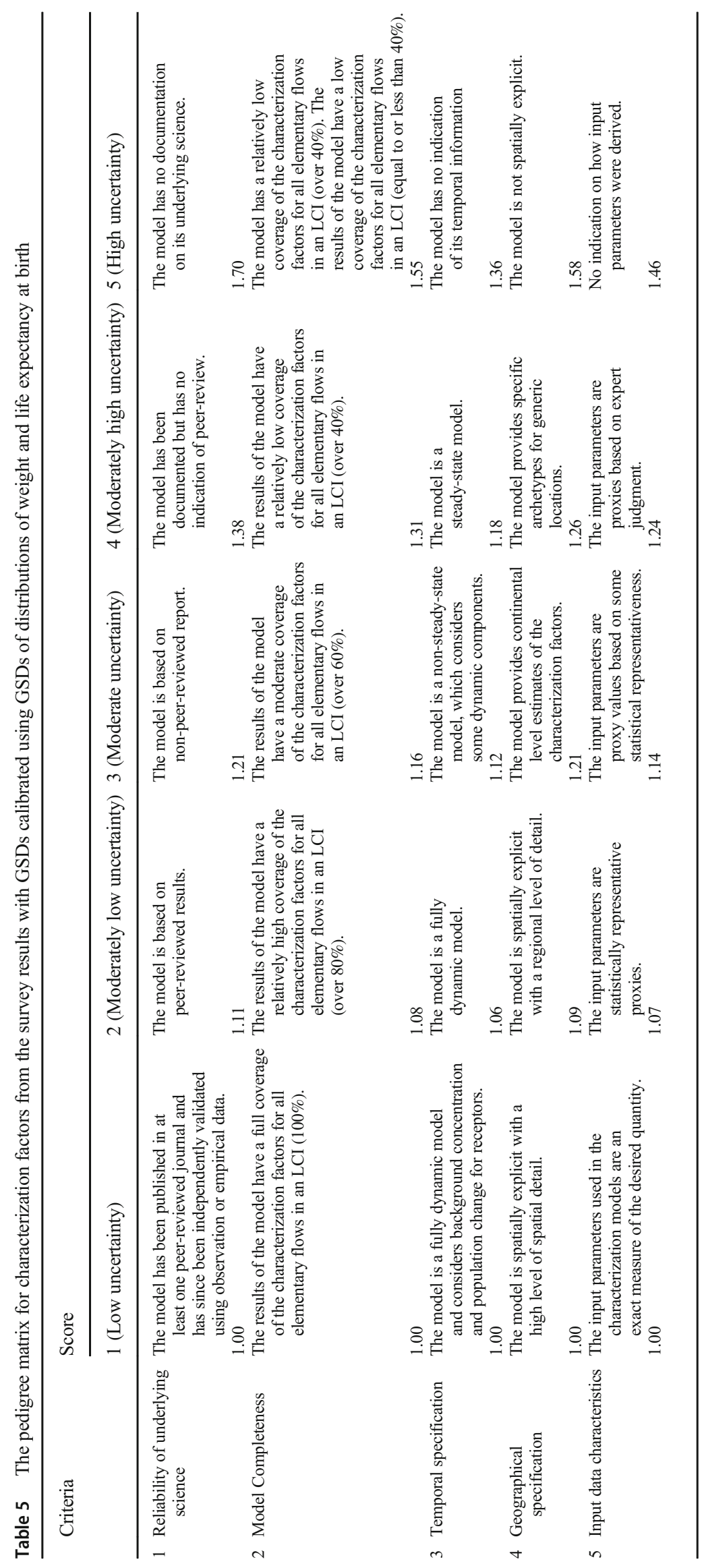




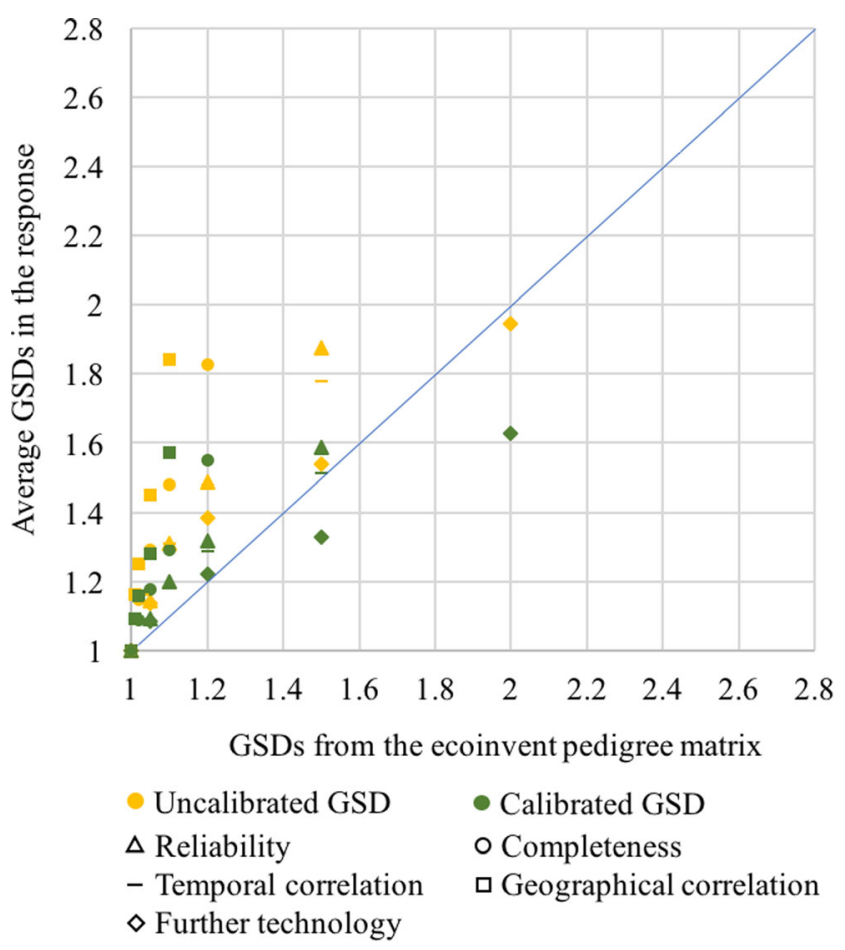

Fig. 3 Comparison of the average GSDs in the pedigree matrix for LCI in the response and the GSDs in the ecoinvent pedigree matrix

were generally higher for characterization factors than for LCI, which was consistent with prior observations in the literature (Owens 1997; Huijbregts 1998b; Clavreul et al. 2012). However, the overall difference in mean GSDs between LCI

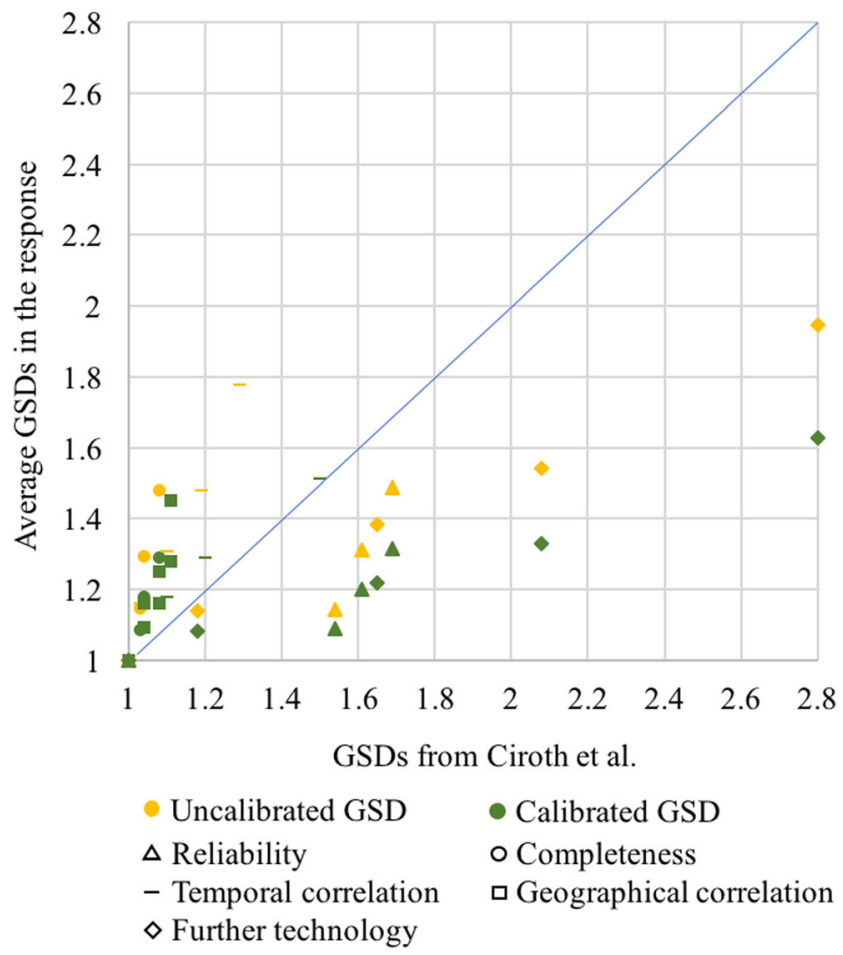

Fig. 4 Comparison of the average GSDs in the pedigree matrix for LCI in the response and the GSDs in Ciroth et al. (2013) and characterization across all criteria was only marginal (3\%). The variations in the level of perceived uncertainties among responses were larger for characterization (coefficient of variance: $24.4 \%$ ) than for LCI (coefficient of variance: $22.4 \%)$.

About half (49\%) of respondents were in favor of using the pedigree method to characterize uncertainty in LCA, while $26 \%$ of the respondents disapproved the pedigree method as an approach to characterize uncertainty. The opinions were sharply divided among the respondents with 6 years or more experiences in LCA, with $19 \%$ of them strongly approving the method versus $15 \%$ strongly disapproving it. In general, the group with more LCA experience was much more skeptical about the use of the pedigree approach in uncertainty characterization.

The respondents perceived that model reliability and geographical correlation were very imporant in determining the variabilities in characterization factors. The two criteria weren't perceived as important for LCI. The respondents generally perceived that temporal correlation was less important in characterizing uncertainty than in LCI.

We found it challenging to apply the pedigree approach to characterization. At the outset, our intent was to create a different pedigree matrix for each impact category and each characterization model. But it became evident that such an approach would lead to a complex questionnaire and that the time commitment of respondents would be exessive. As a result, we went with a broader approach. We believe that the wide variability in responses observed for characterization can be explained in part by the lack of specificity in the characterization model in our survey, which is a major limitation.

Overall, our survey results show that there is no strong consensus among LCA experts on whether the use of the pedigree method for uncertainty characterization in LCA is desirable, while there often is no clear alternative at hand. For example, a UNEP-SETAC Life Cycle Initiative working group recommends that regionalized characterization factors should report uncertainty factors (Mutel et al. 2019), while it is a challenge to develop such uncertainty factors based on measurements. The lack of appropriate methods to estimate underlying variability in LCA data is the main barrier to making uncertainty analysis in LCA mainstream. Given that few disagree on the importance and need of uncertainty analysis in LCA, developing widely accepted methods to estimate underlying variability in LCA data is urgently needed. This need can be met by not only continued research and development by individual researchers but also through systematic efforts by international organizations to identify and build consensus on best practices.

Our survey also confirms that uncertainties in characterization are perceived to be at least as large as those in LCI. Given the virtually non-existent uncertainty measurements in 


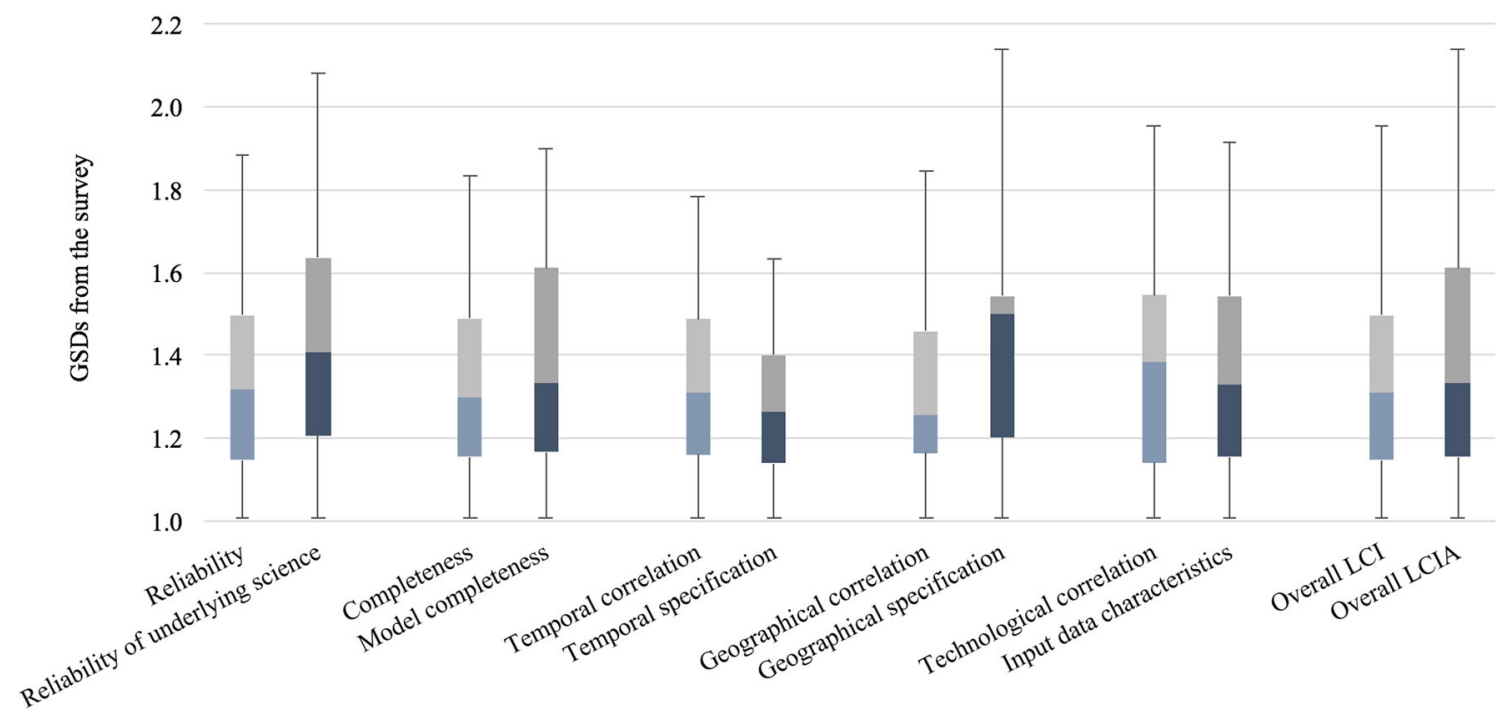

Fig. 5 Comparison between uncalibrated GSDs in the LCI and characterization factor pedigree matrices from the survey. Light blue and gray colors represent the GSDs for LCI criteria, and dark blue and

characterization in today's LCA practices, our results indicate that existing uncertainty analyses in LCA are perceived to cover no more than half of the true uncertainties. Our results, therefore, call for expediting the efforts to measure uncertainties in characterization and other steps in LCIA.

Acknowledgments We are thankful to all 47 respondents who participated in the survey. We thank Dr. Sarah Anderson, Dr. Mark Huijbregts, and Dr. Lucas Laughery for their valuable inputs to this research.

Funding information This work was supported by the Assistance Agreement No. 83557901 awarded by the US Environmental Protection Agency to University of California, Santa Barbara. It has not been formally reviewed by EPA. The views expressed in this document are solely those of the authors and do not necessarily reflect those of the Agency. EPA does not endorse any products or commercial services mentioned in this publication.

\section{References}

Alpert M, Raiffa H (1982) A progress report on the training of probability assessors

Althaus H, Doka G, Dones R, et al (2007) Overview and methodology: data v2.0 (2007). Ecoinvent Cent Zurich $\mathrm{CH}$

Amara RC, Lipinski AJ (1971) Some views on the use of expert judgment. Technol Forecast Soc Chang 3:279-289

Armstrong JS (2008) Methods to elicit forecasts from groups: Delphi and prediction markets compared

Ayyub BM (2000) Methods for expert opinion elicitation of probabilities and consequences for corps facilities. US Army Corps Eng IWR Rep No 00-R-10

Björklund AE (2002) Survey of approaches to improve reliability in lca. Int J Life Cycle Assess 7:64-72 gray colors represent characterization criteria. Each box plot presents the surveyed GSDs for the five uncertainty levels for each indicator

Brown B, Cochran S, Dalkey N (1969) The Delphi method, II: structure of experiments. RAND Corporation, Santa Monica

Cellura M, Longo S, Mistretta M (2011) Sensitivity analysis to quantify uncertainty in life cycle assessment: the case study of an Italian tile. Renew Sust Energ Rev 15:4697-4705

CIA (2018) The world factbook life expectancy at birth. Central Intelligence Agency

Ciroth A, Muller S, Weidema B, Lesage P (2013) Empirically based uncertainty factors for the pedigree matrix in ecoinvent. Int $\mathrm{J}$ Life Cycle Assess 21:1338-1348

Clavreul J, Guyonnet D, Christensen TH (2012) Quantifying uncertainty in LCA-modelling of waste management systems. Waste Manag 32: 2482-2495

Clavreul J, Guyonnet D, Tonini D, Christensen TH (2013) Stochastic and epistemic uncertainty propagation in LCA. Int J Life Cycle Assess 18:1393-1403

Clemen RT, Winkler RL (1985) Limits for the precision and value of information from dependent sources. Oper Res 33:427-442

Cooke RM (1991) Experts in uncertainty: opinion and subjective probability in science. Oxford University Press, Oxford

Cooke R, Goossens L (1990) The accident sequence precursor methodology for the European Post-Seveso era. Reliab Eng Syst Saf 27: $117-130$

Cooper JS, Noon M, Kahn E (2012) Parameterization in Life Cycle Assessment inventory data: review of current use and the representation of uncertainty. Int J Life Cycle Assess 17:689-695

Cucurachi S, van der Giesen CC, Heijungs R, de Snoo GR (2017) No matter-how?: dealing with matter-less stressors in LCA of wind energy systems. J Ind Ecol 21:70-81

Czembor CA, Vesk PA (2009) Incorporating between-expert uncertainty into state-and-transition simulation models for forest restoration. For Ecol Manag 259:165-175

de Franca Doria M, Boyd E, Tompkins EL, Adger WN (2009) Using expert elicitation to define successful adaptation to climate change. Environ Sci Pol 12:810-819

Edelen A, Ingwersen WW (2018) The creation, management, and use of data quality information for life cycle assessment. Int J Life Cycle Assess 23:759-772

Ferrell WR (1994) Discrete subjective probabilities and decision analysis: elicitation, calibration and combination 
Finnveden G, Hauschild MZ, Ekvall T, Guinée J, Heijungs R, Hellweg S, Koehler A, Pennington D, Suh S (2009) Recent developments in life cycle assessment. J Environ Manag 91:1-21. https://doi.org/10. 1016/j.jenvman.2009.06.018

Frey C (1998) Briefing paper part 1: introduction to uncertainty analysis. Dep Civ Eng N C State Univ

Frischknecht R, Rebitzer G (2005) The ecoinvent database system: a comprehensive web-based LCA database. J Clean Prod 13:13371343

Fryar CD, Gu Q, Ogden CL (2012) Anthropometric reference data for children and adults: United States, 2007-2010. Vital Health Stat 11: $1-48$

Funtowicz SO, Ravetz JR (1990) Uncertainty and quality in science for policy. Springer Science \& Business Media

Gavankar S, Anderson S, Keller AA (2015) Critical components of uncertainty communication in life cycle assessments of emerging technologies: nanotechnology as a case study. J Ind Ecol 19:468-479

Geisler G, Hellweg S, Hungerbühler K (2005) Uncertainty analysis in life cycle assessment (LCA): case study on plant-protection products and implications for decision making (9 pp+ $3 \mathrm{pp}$ ). Int J Life Cycle Assess 10:184-192

Gregory JR, Noshadravan A, Olivetti EA, Kirchain RE (2016) A methodology for robust comparative life cycle assessments incorporating uncertainty. Environ Sci Technol 50:6397-6405

Groen EA, Heijungs R, Bokkers EAM, de Boer IJM (2014) Methods for uncertainty propagation in life cycle assessment. Environ Model Softw 62:316-325. https://doi.org/10.1016/j.envsoft.2014.10.006

Hauschild MZ, Goedkoop M, Guinée J, Heijungs R, Huijbregts M, Jolliet O, Margni M, de Schryver A, Humbert S, Laurent A, Sala S, Pant R (2013) Identifying best existing practice for characterization modeling in life cycle impact assessment. Int J Life Cycle Assess 18:683697

Heijungs R (1996) Identification of key issues for further investigation in improving the reliability of life-cycle assessments. J Clean Prod 4: $159-166$

Heijungs R, Huijbregts MA (2004) A review of approaches to treat uncertainty in LCA. Orlando Fla Elsevier

Henriksson PJ, Rico A, Zhang W et al (2015) Comparison of Asian aquaculture products by use of statistically supported life cycle assessment. Environ Sci Technol 49:14176-14183

Hickey AM, Davis AM (2003) Elicitation technique selection: how do experts do it? In: Requirements engineering conference, 2003. Proceedings. 11th IEEE international. IEEE, pp 169-178

Huijbregts MA (1998a) Application of uncertainty and variability in LCA. Int J Life Cycle Assess 3:273-280

Huijbregts MA (1998b) Part II: dealing with parameter uncertainty and uncertainty due to choices in life cycle assessment. Int J Life Cycle Assess 3:343-351

Huijbregts MA, Gilijamse W, Ragas AM, Reijnders L (2003) Evaluating uncertainty in environmental life-cycle assessment. A case study comparing two insulation options for a Dutch one-family dwelling. Environ Sci Technol 37:2600-2608

Hung M-L, Ma H (2009) Quantifying system uncertainty of life cycle assessment based on Monte Carlo simulation. Int J Life Cycle Assess 14:19-27

International Standard Organization (1997) ISO 14040: environmental management-Life cycle assessment-principles and framework

Jaworska JS, Bridges TS (2001) Uncertainty in environmental risk assessment. In: Linkov I, Palma-Oliveira J (eds) Assessment and management of environmental risks. Springer, Dordrecht, p 203-207

Knol AB, Slottje P, van der Sluijs JP, Lebret E (2010) The use of expert elicitation in environmental health impact assessment: a seven step procedure. Environ Health 9:19

Lloyd SM, Ries R (2007) Characterizing, propagating, and analyzing uncertainty in life-cycle assessment: a survey of quantitative approaches. J Ind Ecol 11:161-179
Martin TG, Burgman MA, Fidler F et al (2012) Eliciting expert knowledge in conservation science. Conserv Biol 26:29-38

Maurice B, Frischknecht R, Coelho-Schwirtz V, Hungerbühler K (2000) Uncertainty analysis in life cycle inventory. Application to the production of electricity with French coal power plants. J Clean Prod 8: 95-108

McBride MF, Burgman MA (2012) What is expert knowledge, how is such knowledge gathered, and how do we use it to address questions in landscape ecology? In: Expert knowledge and its application in landscape ecology. Springer, New York, p 11-38. https://doi.org/ 10.1007/978-1-4614-1034-8 2

Meozzi PG, Iannucci C (2006) Facilitating the development of environmental information into knowledge: government agency perspective to improve policy decision-making. In: 4th International Conference on Politics and Information Systems, Technologies and Applications

Moore DA, Healy PJ (2008) The trouble with overconfidence. Psychol Rev 115:502-517

Morgan MG (2014) Use (and abuse) of expert elicitation in support of decision making for public policy. Proc Natl Acad Sci 111:71767184

Muller S, Lesage P, Ciroth A et al (2014) The application of the pedigree approach to the distributions foreseen in ecoinvent v3. Int J Life Cycle Assess 21:1327-1337. https://doi.org/10.1007/s11367-0140759-5

Murphy AH, Daan H (1984) Impacts of feedback and experience on the quality of subjective probability forecasts. Comparison of results from the first and second years of the zierikzee experiment. Mon Weather Rev 112:413-423

Mutel C, Liao X, Patouillard L, Bare J, Fantke P, Frischknecht R, Hauschild M, Jolliet O, Maia de Souza D, Laurent A, Pfister S, Verones F (2019) Overview and recommendations for regionalized life cycle impact assessment. Int J Life Cycle Assess 24:856-865

Nijhof CO, Huijbregts MA, Golsteijn L, van Zelm R (2016) Spatial variability versus parameter uncertainty in freshwater fate and exposure factors of chemicals. Chemosphere 149:101-107

Noshadravan A, Wildnauer M, Gregory J, Kirchain R (2013) Comparative pavement life cycle assessment with parameter uncertainty. Transp Res Part Transp Environ 25:131-138

OpenLCA (2018) User Manual. GreenDelta, Germany

Owens JW (1997) Life-cycle assessment: constraints on moving from inventory to impact assessment. J Ind Ecol 1:37-49

Pfister S, Scherer L (2015) Uncertainty analysis of the environmental sustainability of biofuels. Energy Sustain Soc 5:30

Qin Y, Suh S (2017) What distribution function do life cycle inventories follow? Int J Life Cycle Assess 22:1138-1145

Ragas AM, Huijbregts MA, Henning-de Jong I, Leuven RS (2009) Uncertainty in environmental risk assessment: implications for risk-based management of river basins. Integr Environ Assess Manag 5:27-37

Reap J, Roman F, Duncan S, Bras B (2008) A survey of unresolved problems in life cycle assessment. Int J Life Cycle Assess 13:374 388

Rowe G, Wright G (1999) The Delphi technique as a forecasting tool: issues and analysis. Int $\mathrm{J}$ Forecast 15:353-375

Roy P-O, Azevedo LB, Margni M et al (2014) Characterization factors for terrestrial acidification at the global scale: a systematic analysis of spatial variability and uncertainty. Sci Total Environ 500:270 276

Rypdal K, Winiwarter W (2001) Uncertainties in greenhouse gas emission inventories - evaluation, comparability and implications. Environ Sci Pol 4:107-116

Scherer L, Pfister S (2016) Dealing with uncertainty in water scarcity footprints. Environ Res Lett 11:054008 
Sills DL, Paramita V, Franke MJ et al (2012) Quantitative uncertainty analysis of life cycle assessment for algal biofuel production. Environ Sci Technol 47:687-694

SimaPro (2016) User Manual. PRé Consultants, Netherlands

Slottje P, van der Sluijs JP, Knol AB (2008) Expert elicitation: methodological suggestions for its use in environmental health impact assessments. National Institute for Public Health and the Environment

Sonnemann GW, Schuhmacher M, Castells F (2003) Uncertainty assessment by a Monte Carlo simulation in a life cycle inventory of electricity produced by a waste incinerator. J Clean Prod 11:279-292

Sugiyama H, Fukushima Y, Hirao M, Hellweg S, Hungerbühler K (2005) Using standard statistics to consider uncertainty in industry-based life cycle inventory databases (7 pp). Int J Life Cycle Assess 10: 399-405

US Environmental Protection Agency (2005) Guidelines for carcinogen risk assessment. In: Risk Assessment Forum. US EPA, Washington

van den Berg NW, Huppes G, Lindeijer EW, et al (1999) Quality assessment for LCA. Leiden: CML, Leiden University. (CML Report 152)

Van Der Sluijs JP, Craye M, Funtowicz S et al (2005) Combining quantitative and qualitative measures of uncertainty in model-based environmental assessment: the NUSAP system. Risk Anal 25:481492 von Pfingsten S, Broll DO, von der Assen N, Bardow A (2017) Secondorder analytical uncertainty analysis in life cycle assessment. Environ Sci Technol 51:13199-13204

Weidema BP (1998) Multi-user test of the data quality matrix for product life cycle inventory data. Int J Life Cycle Assess 3:259-265

Weidema BP, Wesnaes MS (1996) Data quality management for life cycle inventories - an example of using data quality indicators. J Clean Prod 4:167-174

Weidema BP, Bauer C, Hischier R, et al (2013) Overview and methodology: data quality guideline for the ecoinvent database version 3 . Swiss Centre for Life Cycle Inventories

Wernet G, Bauer C, Steubing B, Reinhard J, Moreno-Ruiz E, Weidema B (2016) The ecoinvent database version 3 (part I): overview and methodology. Int J Life Cycle Assess 21:1218-1230

Winkler RL, Murphy AH (1968) "Good” probability assessors. J Appl Meteorol 7:751-758

Yang Y, Tao M, Suh S (2018) Geographic variability of agriculture requires sector-specific uncertainty characterization. Int $\mathrm{J}$ Life Cycle Assess 23:1581-1589

Publisher's note Springer Nature remains neutral with regard to jurisdictional claims in published maps and institutional affiliations. 